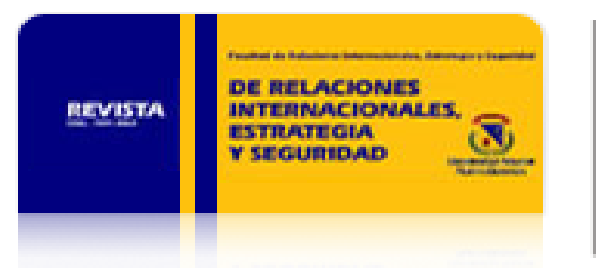

Revista de Relaciones Internacionales, Estrategia y Seguridad

ISSN: 1909-3063

cinuv.relinternal@unimilitar.edu.co

Universidad Militar Nueva Granada

Colombia

Ghotme, Rafat

La historia de las relaciones internacionales en Colombia una ojeada a la literatura sobre la fase republicana, 1820-1903

Revista de Relaciones Internacionales, Estrategia y Seguridad, vol. 2, núm. 2, julio-diciembre, 2007

Universidad Militar Nueva Granada

Bogotá, Colombia

Disponible en: http://www.redalyc.org/articulo.oa?id=92720208

- Cómo citar el artículo

- Número completo

- Más información del artículo

- Página de la revista en redalyc.org

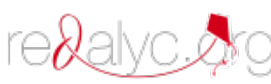

Sistema de Información Científica

Red de Revistas Científicas de América Latina, el Caribe, España y Portugal

Proyecto académico sin fines de lucro, desarrollado bajo la iniciativa de acceso abierto 
rev.relac.int.estrateg.segur.2(2):33-62,2007

\section{LA HISTORIA DE LAS RELACIONES INTERNACIONALES EN COLOMBIA Una ojeada a la literatura sobre la fase republicana, 1820-1903}

Rafat Ghotme

\section{RESUMEN}

En este artículo se pretende mostrar la evolución de las relaciones internacionales en una perspectiva histórica, marcando el hito fundamental de la división entre la disciplina autónoma de las Relaciones Internacionales con un cuerpo teórico y metodológico, y la Historia de las Relaciones Internacionales, heredera de la Historia Diplomática.

Al desarrollar esta última disciplina, mostraremos, sin embargo, que no se constituyó en una escuela como tal en el medio académico colombiano, aunque siguió llevando a cabo investigaciones bajo diferentes tópicos y tendencias de los autores, desde la Historia Tradicional, pasando por el revisionismo, hasta llegar a las historias estructuralistas y marxistas. En último término, se trata de una historiografía de las obras publicadas sobre la "Historia de las Relaciones Internacionales de Colombia en el siglo XIX". 
Palabras Clave: historia de las relaciones internacionales, historia diplomática, revisionismo, equilibrio del poder, subordinación, autonomía, estructuralismo, marxismo, sistema internacional.

\begin{abstract}
This article pretends to show the evolution of the international relations from a historical perspective, marking the fundamental landmark of the division between the autonomous discipline of International Relations with a theoretical and methodological body, and the History of International Relations, inheriting discipline of Diplomatic History. When developing this last discipline, it will be shown, nevertheless, that it was not constituted as an institution of the Colombian academic environment, although it continued carrying out investigations about different topics and tendencies from the authors since Traditional History, throughout the revisionism, until structuralist and Marxist histories. As last term, this is a historiography of published works of the History of the International Relations in Colombia in the XIX century.
\end{abstract}

Key Words: History of the International Relations, Diplomatic History, Revisionism, Balance of the Power, Subordination, Autonomy, Structuralism, Marxism, International System.

\title{
LA HISTORIA DE LAS RELACIONES INTERNACIONALES EN COLOMBIA. Una ojeada a la literatura sobre la fase republicana, 1820-1903.
}

La historia de las relaciones internacionales tiene, metodológicamente, dos puntos de partida tradicionales: el primero es el que se encarga de estudiar la evolución de la disciplina, su aparición en el medio intelectual hasta estructurarse con un cuerpo teórico y epistemológico autónomo, aceptado por buena parte de la comunidad de adeptos; por lo demás, que exista un melting pot inter-paradigmático o inter-disciplinario en las relaciones internacionales en los últimos años, ha enriquecido aún más el debate, antes que aplastar el carácter autónomo, en la evolución de la disciplina (Attinà, 2001). Un segundo aspecto es el que muestra el estudio de las relaciones internacionales enfocado en la "perspectiva de las investigaciones históricas", al decir de Renouvin (1960, I, Intro. Gen.: IX), esto es, aquella disciplina que busca mostrar las transformaciones, junto con sus causas, de las relaciones que se dan entre los pueblos y los estados. Ahora, buscar mostrar las transformaciones, causas y alcances que adquieren estas relaciones -en el sentido del acrecentamiento del conflicto- no sólo requiere de una profunda visión intelectual de una «investigación de las explicaciones» que los causan, 
sino que debe incorporar el estudio de los hechos, eventos o acontecimientos que le dan sentido a la perspectiva histórica ${ }^{1}$. En ese sentido, el segundo aspecto aparece matizado por cuestiones teórico-metodológicas, por un lado, y por cuestiones empírico-históricas, por el otro. Si sólo estructuramos la investigación en las «explicaciones», estaríamos limitando la disciplina a una sociología de las relaciones internacionales (Tickner, 2002:136 y ss., por ejemplo, asume la posición sociológica) ${ }^{2}$. Esta no es nuestra intención.

Nuestra pretensión en este artículo es, más bien, desentrañar la evolución de la disciplina de la Historia de las Relaciones Internacionales en Colombia durante el periodo republicano (1820-1903). Justo acá se debe hacer otra precisión: en este ensayo no vamos a (re)elaborar la historia de las relaciones internacionales en Colombia, sino que se van a abordar los estudios que se han publicado en torno a la historia de las relaciones internacionales de Colombia desde que nace a la vida independiente hasta la separación de Panamá. En otras palabras: se trata de incorporar un tercer punto de partida al hacer un estudio historiográfico, estructurado de acuerdo a los parámetros del segundo aspecto atrás nombrado (en especial el referente al

\footnotetext{
${ }^{1}$ En mayúscula, la Historia de las Relaciones Internacionales es entendida como el estudio de las explicaciones que causan una situación conflictiva -o la alteración y evolución- en el curso de las relaciones entre los pueblos y los estados; incluye, por tanto, los acontecimientos y las minuciosas negociaciones que devela el horizonte de las cancillerías, la conducción de la guerra y la actuación de los hombres y mujeres que materializan la política exterior de sus estados nacionales.
}

${ }^{2}$ La Historia de las Relaciones Internacionales, como disciplina científica, no debe ser confundida con la Historia, la Historia Internacional o las Relaciones Internacionales en sí. Como disciplina científica, las Relaciones Internacionales, a secas, sin embargo, cada vez más descubre una epistemología historizada, hasta el punto de que pueda ser considerada una isla más de la Historia. Puesto que tradicionalmente se ha venido considerando a las Relaciones Internacionales como una sociología del escenario -sociedad-internacional, la pretensión más elevada de ciencia que pudo adquirir aquélla se trazó a través de lo que conocemos comúnmente como sociología histórica, una sociología histórica internacional. La sociología histórica estudia las interrelaciones significativas (acciones) y los contextos estructurales (sistema) a través de casos comparativos de los diferentes espacios culturales y sociales, estableciendo generalizaciones o similitudes a partir de un concepto (Skocpol, 1984; Fulbrook y Skocpol, 1984:192).

Pero es bastante sabido que toda pretensión sociológica tiende a desconocer algunos sectores de la historia, como los detalles o minucias del acontecer y la vida cotidiana de una parcela de la realidad, que en nuestro caso se trata de la Sociedad Internacional o de la relación de la política exterior con el sistema internacional. En Relaciones Internacionales ha sido bastante usada la perspectiva sociológico-histórica de Wallerstein, enraizada en la idea totalizadora de "interpretar eventos" a lo largo de la historia a través de una unidad de análisis conocida como sistema-mundo, pero el hecho es que un concepto o teoría pude desconocer que el "registro histórico es complejo, y buena parte de esta complejidad no puede ser dominada por una perspectiva de sistema-mundo" multiabarcadora (Ragin y Chirot, 1984:305). Creemos que este vacío lo puede llenar la Historia de las Relaciones Internacionales, o de lo que en algunos otros escenarios hemos venido considerando: las Relaciones Internacionales como Historia del Presente. Sin embargo, tampoco es nuestra intención abordar este aspecto de la disciplina aquí. 
teórico-metodológico), y en menor medida en el primer aspecto, aunque su interrelación sea inevitable ${ }^{3}$. Veamos brevemente cómo se ha dado esa interrelación en Colombia.

En el medio académico colombiano, como ocurrió en casi todo el mundo, el estudio de las relaciones internacionales comenzó por ser una ramificación del derecho internacional y la historia diplomática o de los tratados; a partir de la finalización de la segunda guerra mundial en algunos países de América Latina, como Chile o México, predominó la tendencia por separar cada vez más los estudios del derecho y la historia para darle paso a un cuerpo teórico incipiente de las relaciones internacionales como disciplina autónoma (Tickner, 2002:63-64). En Colombia, sin embargo, esta tendencia sólo arreció en la década de 1980, con la creación del Centro de Estudios Internacionales y la carrera de Relaciones Internacionales en contadas universidades de Bogotá. Con la aparición de la carrera de Relaciones Internacionales y Diplomacia en la Universidad de Bogotá Jorge Tadeo Lozano, a fines de la década de 1950, se mantuvo la esencia de los estudios formales de la diplomacia y el derecho internacional, sin manifestar, por tanto, algún cambio o novedad en la disciplina. Lo novedoso radicó en que se dejó de enseñar la historia diplomática y el derecho internacional en las Facultades de Derecho, la Academia Colombiana de Historia o la misma Cancillería, ésta última con un programa de conferencias dictado a los funcionarios y especialistas del tema ${ }^{4}$, para pasar a ser enseñada institucionalmente en una facultad autónoma.

\footnotetext{
${ }^{3}$ Como estudio historiográfico, este ensayo se basa esencialmente en la obra del profesor Bernardo Tovar, uno de los principales promotores de la investigación de la "historia de la historia» (Tovar, 1995). A decir verdad, en el medio académico-histórico colombiano son casi nulos (por no decir que inexistentes) los estudios de historiografía de las relaciones internacionales; a lo sumo, las referencias de historia social, económica y de la cultura se han limitado a hacer un encomiado rechazo a los parámetros de la historia patria o tradicional (conocida también entre los historiadores franceses y anglosajones como Historia Diplomática), por considerarla ingenua y anacrónica, desvirtuadora de los procesos de formación social que se proyectan paralelamente a la vida y obra de los grandes hombres. Aquí se ofrece, por tanto, un primer esfuerzo personal por analizar las corrientes de pensamiento circunscritas a la obra de los historiadores e internacionalistas que estudiaron la política exterior de Colombia en el siglo XIX. Esperamos de ese modo que surjan nuevos esfuerzos y mentes dispuestas a corregir y ampliar el horizonte aquí expuesto.

${ }^{4}$ Sobre tales Conferencias, véase las memorias del profesor de la Universidad Nacional, Meyer-Lindenberg, quien en 1937 fue contratado por la Cancillería con ese fin. En la primera mitad del siglo XX se seguía enseñando la Historia Diplomática y el Derecho Internacional en las Facultades de Derecho, como las únicas asignaturas que se encargaban de analizar el sistema internacional, el derecho de gentes y la política exterior, tradición heredada de la segunda mitad del siglo XIX. Los más insignes autores, profesores y funcionarios de la cancillería de aquel entonces eran personajes de la talla de Antonio José Uribe, Fabio Lozano y Torrijos, Jesús María Yepes, y Laureano García Ortiz, además de extranjeros como el citado profesor Hermann Meyer-Lindenberg. Con esa y otras pocas excepciones de profesores dedicados exclusivamente a la cátedra, los demás, la mayoría, se caracterizaban por reunir los tres componentes básicos del "internacionalista": publicistas, catedráticos y funcionarios, componentes que, por lo demás, también reunían los internacionalistas del resto del hemisferio occidental.
} 
Con esta separación quedaba claramente marcado el rumbo de dos disciplinas: las Relaciones Internacionales, con su cuerpo teórico-metodológico independiente (aunque, como se dijo, incipiente), por un lado, y el de la Historia de las Relaciones Internacionales, heredera legítima de la Historia Diplomática, por el otro ${ }^{5}$. Con todo, la misma disciplina de las Relaciones Internacionales aún le sigue debiendo prestancia a la Historia y al Derecho Internacional ${ }^{6}$. Sin embargo, la disciplina de la Historia de las Relaciones Internacionales en Colombia no se estructuró como tal en una escuela institucionalizada como si lo hicieran a lo largo de la segunda mitad del siglo XX las Relaciones Internacionales, con escuelas o facultades autónomas. Pero esto no impidió que los estudiosos de la Historia Diplomática y el Derecho Internacional siguieran abordando el sistema internacional con las tradicionales y las nuevas perspectivas de la investigación histórica.

Al hacer el balance de las obras publicadas que estudiaron la política internacional de Colombia durante el periodo 1820-1903, se pudo detectar que éstas siguieron las mismas tendencias que se desarrollaron en la disciplina histórica en el mundo occidental. Los intelectuales colombianos, más allá de su originalidad y de su forma de percibir la historia de los acontecimientos dentro del contexto cultural adscrito a su obra, estuvieron fuertemente influenciados por las corrientes intelectuales plasmadas en los estudios de los historiadores, políticos e intelectuales europeos y norteamericanos. Tales corrientes son dos básicamente: i) la Historia Tradicional, que en la versión de las relaciones entre los estados y los pueblos, se conoce como Historia Diplomática; ii) la Historia Revisionista, que en las relaciones internacionales va desde los estudios de la Política Internacional, la subordinación y el autonomismo, hasta las formas de imperialismo y neocolonialismo en sus diversas gradaciones y fases históricas. Existe una versión revisionista intermedia, que mezcla los estudios de historia diplomática con las fuerzas profundas y la evolución lenta de los caracteres civilizacionales de la vida material y espiritual incrustados en la mente de los pueblos y los hombres y mujeres responsables de la política exterior. Más adelante analizaremos las obras representativas de cada

\footnotetext{
${ }^{5}$ Más arriba se había dicho que las Relaciones Internacionales podrían quedar reducidas a una Historia del Presente que englobaría diversos niveles de análisis (internacional, regional o local), y, en ese sentido, la disciplina sería una isla más de la historia general y no una ramificación de la sociología (escuela francesa) o la ciencia política (escuela norteamericana). Puesto que en este ensayo no hay lugar para desarrollar este argumento, podemos seguir utilizando lo más comúnmente aceptado, es decir, que las Relaciones Internacionales y la Historia son dos disciplinas autónomas, o que la primera no es la segunda (Duroselle, 1998).

${ }^{6} \mathrm{Si}$ bien las primeras tendencias de análisis de las relaciones internacionales en América Latina y Colombia se basaron en estudios como el de la dependencia, el desarrollo «hacia adentro», el autonomismo, o cosas similares, el hecho es que en Colombia tuvo un fuerte eco el análisis histórico estructural de las relaciones internacionales del Centro de Estudios Internacionales de la Universidad de los Andes (léase Pardo, Tokatlián, Cardona, Drekonja o Randall), o la escuela francesa (la praxis de la disciplina) implantada por la Universidad Externado de Colombia (Tickner, 2002:77 y ss.).
} 
una de estas tendencias. Lo que interesa por ahora es presentar algunos de sus principales aspectos conceptuales y debates intelectuales:

Como heredera de la Historia de los Tratados y el Derecho Internacional Clásico, la Historia Diplomática configuró una forma de narración y estructura historiográficas consistente en incorporar la historia nacional al summum del concierto de las naciones civilizadas, cristianas y racionales. Para acometer tal necesidad, los académicos recrearon una narración que llevaba consigo un mensaje mítico de evocación y retorno al pasado nacional, repleto de héroes y hombres de estado que dirigían la política interna y externa de Colombia. En ese sentido, si bien estaba adscrita y pendía de los parámetros de la Academia Colombiana de Historia, constituye este el primer y más acabado intento de institucionalizar la Historia Diplomática colombiana. Por otro lado, la historia revisionista -transicional o estructuralista- supuso, además de la superación de los límites que acusaba la historia tradicional, que existen factores económicos y sociales que configuran la elaboración de la política exterior colombiana. Entre esos factores o entornos sobresalían el sistema monetario internacional, el comercio entre las naciones, la política de reconquista e imperialismo de las grandes potencias y el contexto sociopolítico en el que se podría ubicar el derecho internacional. Presentados sus prospectos conceptuales, sobrevenía entonces la batalla por adecuar metodológicamente sus historias: ¿qué determina la política internacional, el hombre de estado, la estructura del equilibrio del poder -con la subsiguiente dispersión de fuerzas en el sistema-, o las políticas imperiales que por azar le correspondía a uno u otro estado capitalista en expansión? Antes de pasar a discernir sobre estos interrogantes, sobra recalcar que todas las tendencias reconocían que la idea básica era desentrañar las determinantes de la política exterior colombiana, pese a los énfasis de una u otra escuela, ya sea el socioeconómico (imperialismo) o político (equilibrio del poder).

Por un lado, la Historia Diplomática se consideró insuficiente para explicar los fenómenos que imbrican los determinantes socioeconómicos que subyacen en la política internacional. Basada en una narración de detalles y anécdotas que ilustran las instrucciones que legaron los gobiernos a sus funcionarios -por lo que se descubre que los detalles de la negociación y sus efectos son fundamentales-, esta narración, se decía, comenzó a ser desplazada por las historias con un fuerte influjo determinista social y económico, incluyendo las fuerzas subyacentes de la psicología colectiva. Ese desplazamiento se debió ante todo a la idea de que la historia tradicional se apoyaba en la seguridad que le proporcionaba el "documento" diplomático. El documento era -y sigue siendo- la fuente y vida de la narración histórica. Del documento provenía su interpretación «objetiva» de la historia, que, paradójicamente, obedecía más a una visión romántica/heroica de la vida y la sociedad. ¿Pero suministra el documento por sí mismo las causas del evento circunscrito en la actividad diplomática? El documento aporta elementos valiosos tanto para los detalles de la negociación como para la interpretación, pero ciertamente omite los eventos del entorno que los motivan, eventos que catalogamos como 
determinantes del sistema. El problema de la Historia Diplomática no es su fe intacta en la obra de los grandes hombres: su crítica estriba más bien en su método.

Del mismo modo, la historia basada en las explicaciones de la vida material y espiritual de los pueblos como determinantes de la política internacional, comenzó a desplazar paulatinamente la obra de los historiadores tradicionales y, por tanto, la actividad de los hombres de estado como lo concluyente. ¿Pero reconoce esta historia que los factores económicos y sociales penden en buena medida -si no siempre- de las motivaciones de los hombres de estado y la ideología política? Existen buenas razones para creer que los determinantes socioeconómicos deben elaborar un marco explicativo general. Mas las estructuras económicas, e incluso los sentimientos colectivos, por más que arrastren consigo mismo un corolario de pasiones y emociones, necesitarán en buena medida de los grandes conductores de sociedades enteras, sus impulsos y maneras de pensar y actuar.

Este ensayo está guiado por la escuela francesa de la Historia de las Relaciones Internacionales, es decir, la escuela que incorpora en su estudio, por un lado, las «fuerzas profundas», y la actuación decisiva de los grandes conductores de la política internacional, por el otro. Las «fuerzas profundas», en el sentido que las expuso Renouvin (1960, I, Intro. Gen.; 1960, II, I), están configuradas por movimientos económicos, sociales y culturales que subyacen como telón de fondo de la política internacional, entendida ésta como el escenario donde se materializa el conflicto (guerra y paz internacionales). Como veremos, sin embargo, las fuerzas profundas no debieran desvirtuar la actuación decisiva de los hombres/mujeres de estado, puesto que son ellos quienes le imprimen el impulso a los hechos relevantes de la sociedad y los Estados. Sin pretender alargar más aquí el viejo debate sobre qué determina a qué (si la estructura al hombre/mujer, o a la inversa), sólo basta con decir que si bien los/las grandes hombres/mujeres encargados de diseñar la política exterior suelen estar convencidos que dominan el curso del acontecer histórico -pese a que no sea el hecho-, es más aceptado que esos personajes puedan dar curso a una o más formas posibles de solución política como consecuencia de algún acontecimiento histórico inevitable (v. gr., la Revolución y sus posibles salidas institucionales impuestas por el "gran hombre"). Siguiendo a Renouvin (1960, I, Intro. Gen.: XII), "La idea básica, es decir, el estudio del papel desempeñado por los estadistas, sigue siendo válida" ${ }^{7}$; idea que se refuerza si se aceptan los condicionantes socioeconómicos reflejados en algún lugar de la realidad histórica.

Dos palabras más: hecho el balance de las obras que analizaron la política internacional de Colombia en el siglo XIX, nos encontramos que no existe una obra de síntesis que refleje el

\footnotetext{
${ }^{7}$ Dice Renouvin (1960, I, Intro. Gen.: XIV): “Estudiar las influencias que se ejercen sobre las relaciones internacionales, despreciando el conjunto de circunstancias de un momento o de una época, sería falsear la perspectiva histórica".
} 
carácter totalizante de las relaciones internacionales en perspectiva histórica. Son más bien obras circunscritas en un tiempo largo con sus respectivas etapas de la vida constitucional y presidencial (historia tradicional); obras que recrean una categoría de análisis, como la del equilibrio del poder, el imperialismo o el neocolonialismo, dándole relieve a una teoría que a veces resulta difícil de colegir en el laboratorio de la historia. Si bien estas obras están adaptadas a una escuela o tendencia de pensamiento (academicismo, estructuralismo o marxismo), difícilmente aceptan incorporar uno u otro de los elementos propuestos por las diferentes escuelas, haciendo aún más difícil el lugar a la síntesis. En cualquier caso, esto no es una obligación para el intelectual: casi todos terminamos diciendo que somos partidarios del eclecticismo, pero en la práctica, cuando emprendemos la escritura de un trabajo, descendemos lentamente por la línea divisoria entre las tendencias de pensamiento, y acabamos por catapultar cualquier pretensión totalizante a favor de nuestra predilección filosófica.

Por último, cabe advertir que sobre los dos puntos de partida atrás referidos sigue existiendo una validez universal que no pretende ser superada acá, es decir, que el tercer punto de partida (el historiográfico) sólo es útil de manera contingente en la medida que pueda ser superada la aparente ausencia de una obra de síntesis. El balance historiográfico, por tanto, es un punto de partida. Partiendo de esta premisa, abordaremos el estudio de las obras representativas de las dos tendencias básicas que se presentaron en Colombia, tratando de incorporar un balance crítico con los lineamientos de la Historia de las Relaciones Internacionales.

\section{LA HISTORIA DIPLOMÁTICA EN COLOMBIA}

Un primer intento de aproximación al estudio de las relaciones internacionales de Colombia, desde la perspectiva de la investigación histórica, sitúa la literatura bajo la rúbrica de la Historia Diplomática o entre los gobiernos. Con el propósito de explorar las condiciones que determinan el decurso de las naciones, su singularismo y el aporte que cada una de éstas hacen al sistema internacional, la Historia Diplomática se basa en un derrotero de narraciones cronológicas de acontecimientos, de descripciones minuciosas que buscan "redactar un manual de doctrinas sacadas de los textos mismos de nuestros diplomáticos como de las actitudes sobresalientes" (Vásquez Carrizosa, 1996, I:27). Basados en la insustituible "objetividad del documento", estas obras diseñan una historia hecha por hombres de estado o héroes y cancilleres, quienes conducen sociedades con el solo prurito de su genio, virtudes y errores. Vásquez Carrizosa (1996, II:481), uno de los principales exponentes de la Historia Diplomática de Colombia, a pesar de afirmar que la política interna y la exterior están estrechamente entrelazadas, el desenvolvimiento de ésta última depende realmente de las decisiones, aciertos y fallas de los gobernantes. 
Son precisamente los "grandes hombres» quienes reflejan el carácter y genio peculiar de su nación. Por esa razón, son «ellos» quienes pueden instrumentalizar los aportes de su respectiva nacionalidad en el concierto de las naciones ${ }^{8}$. El afán por incorporar a Colombia dentro del concierto de las naciones civilizadas no sólo era una cuestión de las historias nacionales, propia de las narraciones históricas del siglo XIX (desde Vico y Herder, hasta Ranke y Toynbee), en las que sobresalía el aporte particular de su genio y espíritu nacional a la civilización universal toda; lo era, también, una cuestión de las relaciones entre los pueblos cristianos y civilizados, prestos a defender el valor de la razón, la soberanía y los parámetros del sistema imperante (Rivas, 1961:749).

Este estilo de historiar se consagró con el «sentido» de la Historia Universal elaborado por el historiador inglés Toynbee, hallado en "la verdadera razón para explicar y entender muchos de los acontecimientos de nuestra historia" (Caycedo, 1956:291). Cuando el historiador inglés visitó Colombia, los miembros de la Academia Colombiana de Historia, es decir, los más insignes representantes de la Historia Tradicional -y por tanto Diplomática-, admitieron que la obras de Toynbee "constituyen una contribución fundamental al conocimiento del pasado de la Humanidad" (Caycedo, 1956:289). ¿En qué consiste eso de hallar «la verdadera razón de los acontecimientos» en la obra de Toynbee? La misma Academia lo respondió en el homenaje que le hizo al visitante inglés: a) en su imaginación para reconstruir el pasado con maestría y lógica; b) en su confraternidad universal; y c) en su profundo sentido de religiosidad, "que sirve a la vez de inspiración y de clave al misterio de la historia" (Caycedo, 1956:292).

Aunque aquí podemos denostar de un supuesto discurso eurocéntrico, cristiano y universal, en la obra de Toynbee y los académicos colombianos se reconoce la existencia de una comunidad que evoluciona en la línea unívoca de la armonía y la paz perpetua. Una de las conferencias de Toynbee que felicitaron los académicos fue la de su "teoría del choque de civilizaciones, que había sido anteriormente materia de una interesante sección de su libro

\footnotetext{
${ }^{8}$ Con Ranke el historicismo adquirió plena dignidad. Mientras que en Herder la historia de los pueblos dimanaba de una relación dinámica entre la civilización vegetativa (desde abajo) y la idea neoplatónica de un ente superior (lo divino) como origen de todo el universo (Meinecke, 1943:332 y ss.), en Ranke la totalidad histórica, aunque concibió su fin en la consecución de una civilización universal de tipo cristiano, la causalidad histórica estribaba en una entidad concreta, el Estado. Los móviles de la historia para Ranke "fueron aquellos que dimanaban del interno principio de vida del estado en su entrelazamiento con todos los acontecimientos interiores y exteriores en la momentánea constelación universal" (Meinecke, 1943:501). Las pequeñas y grandes proezas nacionales, los acontecimientos y la realización de las necesidades humanas, fueron concebidas como la obra de grandes personalidades que a su vez eran determinados por las necesidades vitales de los estados. Los Estados son lo que son, creyeron los pensadores historicistas del siglo XIX y parte del XX, por correr en la línea del progreso, evolución, revitalización y decadencia de las artes y el pensamiento, la ciencia y la técnica, el espíritu y el genio nacional. Para una referencia general sobre la matriz cultural del nacionalismo, cfr. Smith, 1997:77-82.
} 
"El Mundo y el Occidente»" (Caycedo, 1956:290). ¿A quién correspondía encauzarla? Todo indica que a la civilización occidental. A América Latina, por ejemplo, por ser la consecuencia de una fusión o «absorción» de dos razas, la oriental y la occidental, la cuestión se circunscribía a "un problema de biología individual". La teoría de la "difracción» de Toynbee era apenas un paliativo: "[...] para determinar, según la bella comparación analógica formulada por usted, los efectos de la difracción en que se descompuso el espectro luminoso de la cultura hispánica al topar con la resistencia del prisma de la población aborigen" (Caycedo, 1956:291) ${ }^{9}$. Sin embargo, los académicos admitieron en su obra que el carácter de la nacionalidad en la América Hispana constaba de un fuerte linaje aborigen, vínculo indígena que por su lengua y cultura, habíale dado el sello distintivo a las naciones: las relaciones entre éstas estaban determinadas, y esto era novedoso, por su vinculación histórica, geográfica y cultural (Bákula Patiño, 1957:89). Con todo, se debe advertir que en la obra de los académicos el papel primario en la conducción de las naciones, y por tanto de su política exterior, recaía en el "el tipo perfecto del diplomático", esto es, en el hombre de origen latino y cristiano (Otero, 1935:222).

A Bolívar, por supuesto, se le atribuye un papel primario. Otros hombres conformaron el estrado de la etapa gloriosa e irrepetible de la política exterior colombiana: acompañaban a Bolívar hombres de la talla de Zea, Santander y Gual (Urrutia, 1917, 1941). Según Urrutia (1941), la política exterior colombiana había nacido en la era de Bolívar, y que los "hechos culminantes", sus directivas, doctrinas y principios siguieron su trayecto "en el curso de más de un siglo". Urrutia (1941:5), quizás el primer historiador que sistematizó la obra de la diplomacia colombiana, enfatizó en que "la creación de Colombia obedecía en los propósitos de Bolívar a sus planes militares de Libertador, a su política de fundador y organizador de naciones". Sin duda, en el fondo de este discurso romántico, idealista, se incrustaban los anhelos y esperanzas de un pueblo que históricamente se las vio con la dominación y el imperialismo, primero contra España, luego contra Gran Bretaña y Estados Unidos ${ }^{10}$.

\footnotetext{
${ }^{9}$ Aunque en una perspectiva «inversa», me parece que la postura del profesor Henry Cancelado adopta la teoría de la difracción de Toynbee para concebir el sistema internacional contemporáneo a partir de la diferenciación positiva de las culturas y sus interrelaciones (cfr. Cancelado, 2007, II, I); del mismo modo, el profesor Manfred Grautoff (2007) ha sido más radical al asumir la posición «liberal» de concebir el rumbo del sistema nacionalinternacional en la vía del desarrollo hacia una especie de civilización capitalista.

${ }^{10}$ Como dato curioso, la obra de Urrutia, Laureano García Ortiz, Antonio José Uribe, Fabio Lozano y Torrijos, y Jesús María Yepes, los autores primigenios de la historia diplomática de Colombia, siempre mantuvieron su fe intacta en los más altos intereses morales de Estados Unidos en la conducción de la civilización occidental; más allá del romanticismo y positivismo, interesante paradoja de sus narraciones históricas, incluso avanzado el primer medio siglo XX y lo que los nacionalistas Ilamaban el indignante episodio de Panamá, estos autores aún seguían imbuidos por el pensamiento americanista de percibir a Estados Unidos como una potencia que actuaba por la promoción de la libertad y la democracia en el mundo. A Europa, por el contrario, la percibían como el agente imperialista por excelencia, aún cuando Estados Unidos y Europa tenían las mismas intenciones expansionistas aunque con diferentes métodos.
} 
A Bolívar, además, lo consagraron como el autor de toda una obra continental y mundial, no sólo por ser el directo responsable de la política exterior durante los años 1819-1830, sino por su espíritu irradiador de los ideales eternos de la solidaridad latinoamericana del siglo XIX, consecuencia del "desarrollo lógico del pensamiento bolivariano" (Yepes, 1955:208). Para la mayoría de estos autores, el pensamiento internacional de Bolívar no queda limitado únicamente en el trasegar del panamericanismo. Más aún, "la misma Sociedad de las Naciones y la Organización de las Naciones Unidas no son sino la traducción, en una escala mundial, de los proyectos que Bolívar preconizó para el Nuevo Mundo" (Yepes, 1955:113; Urrutia, 1941:123 y ss., 141 y ss). Como se dijo más arriba, el análisis de las relaciones internacionales estaba fuertemente entrelazado con el Derecho Internacional y la Historia Universal, dándole un sentido teleológico a sus obras a partir del genio creador de uno de sus héroes favoritos. En estos autores colombianos dominaba más bien el espíritu clásico de percibir el Derecho Internacional como una evolución sistematizada y lógica irradiada por el concurso de los grandes hombres, que, sin duda, eran los creadores de una vasta y colosal obra de codificación del derecho internacional ${ }^{11}$; en ese sentido, creían fervorosamente que con la participación de un gran hombre en la Sociedad Internacional se armonizarían los más altos principios morales de una civilización universal, pacífica y racional.

En cierto modo, la idea de una gran confederación internacional obedecía a aquellos principios idealistas. En las mentes de los antiguos, los renacentistas y, en el siglo XIX, de los románticos seguidores de la obra de Grocio y Kant, esta idea había sufrido serios traspiés pese a la ingente labor intelectual de sus más fervorosos creadores. Pero a Bolívar le correspondió el destino de ser su gran realizador, aún cuando sólo se llevó a cabo cien años después de su muerte (Urrutia, 1941:167 y ss.). Al "Bolívar internacionalista" de Raimundo Rivas (1938) lo habían antecedido ilustres americanistas que idealizaban una confederación internacional garante de la paz, tales como el chileno Juan Martínez de Rosas, el peruano Juan de España, el centroamericano Cecilio del Valle o el argentino Bernardo Monteagudo. Mas

\footnotetext{
"la idea de una liga de naciones, tan antigua casi como la humanidad, que halló en Grocio, en la primera mitad del siglo XVII, un elocuente expositor, y más de centuria y media después en Kant al filósofo propagador; ese proyecto que no pudo realizar en la vieja Europa la política hábil y plena de porvenir de Enrique IV de Francia, debía encontrar en Bolívar al primer jefe de Estado a quien cupiera el laurel de proponerlo por vez primera, en forma oficial y solemne" (Rivas, 1938:672).
}

La dirección de la política externa del estado colombiano, entonces, tiene un rumbo ascencional, positivizado por medio de los actos de los hombres políticos y motivada por el espíritu del

\footnotetext{
${ }^{11}$ Esa visión suponía que la adopción del enfoque sociológico, de la contextualización de las realidades sociopolíticas, en conjunto con el dominio de las normas (léase Máx. Huber o Dieter Schindler), para estudiar el Derecho Internacional, era prácticamente nula.
} 
REVISTA DE RELACIONES INTERNACIONALES, ESTRATEGIAY SEGURIDAD

legalismo-civilismo ${ }^{12}$. Esto quiere decir que la política exterior colombiana obedece al influjo de las ideas políticas, las circunstancias de orden interno y las condiciones de vida material

\begin{abstract}
12 Por lo dicho hasta ahora, puede quedar la sensación de que estas historias eran excesivamente ingenuas, románticas y carentes de una estructura sólida. Para evitar caer en ese error, sobre todo como lo hacen los estructuralistas-marxistas (v.gr. Díaz Arenas; Infra, nota 20), se deben aclarar varias cosas. Según Yepes (1955:143), las conferencias y tratados celebrados en la América Latina antes del primer Congreso Panamericano de 1890, buscaban, en primer lugar, "organizar la defensa colectiva y solidaria de los Estados interesados, contra los peligros que amenazaban su independencia y soberanía; y, en segundo lugar, realizar, sobre todo, la aspiración tradicional de crear entre ellos una asociación íntima de 'naciones hermanas'". El embate de las potencias europeas había impelido a las naciones latinoamericanas a buscar mecanismos para organizar la sociedad internacional bajo el principio de la igualdad jurídica, su democratización, el mantenimiento de la paz y la seguridad continental, preservar la independencia y su integridad territorial, la solución de conflictos por medio del arbitraje, la libertad de navegación de los mares, y los tratados de unión, liga y confederación, que hacían posible la libre circulación de personas (ante todo las de clase alta) y bienes (Urrutia, 1920,1928; Rivas, 1961:749).
\end{abstract}

Sin embargo, la mayoría de estos autores eran "conscientes» de que tales confederaciones eran impracticables, "inconvenientes", pues en el espíritu de los gobiernos latinoamericanos abundaban "malos procederes" que comprometerían "por los errores del Gobierno de una de las Repúblicas la paz de las otras" (Urrutia, 1920:58; también, Rivas, 1961; Caicedo Castilla, 1974). Cuando Colombia no aprobaba uno de esos "procederes", además, los historiadores solían defender la posición del Gobierno:

“No significaba esta conducta de Colombia en manera alguna una deserción de la causa americana, ni un alejamiento de la política y de las ideas que el Libertador había dejado a nuestros hombres públicos como una tradición, como un legado de su gloria: lo que los hombres sobresalientes de Colombia creían era que los tratados de liga y confederación quedarían como meramente nominales mientras no se adoptasen puntos de partida idénticos en el Derecho Público, tanto interno como externo" (Urrutia, 1920:58).

Partiendo de la idea "justa» de que había necesidad de extirpar "lo oligarquía militar, moralizando la lucha de los partidos", ¿podría ser esta una forma que desde las Relaciones Internacionales explique el establecimiento de militarismos en América Latina, para encauzar la legitimidad anti-expansionista de Europa? En cierto modo, sí. Incluso los congresos latinoamericanos (1826-1889), casi todos en torno al arbitraje, no se ratificaron, puesto que, como consecuencia lógica de la amenaza de reconquista europea, los estados latinoamericanos se dedicaron a buscar los mecanismos para defender su soberanía incluso en el caso de tener que impugnar los lazos de fraternidad y unión con los estados de la región. Según Urrutia (1920:59), "Amenguado el peligro que se creía inminente cuando la escuadra española bombardeaba a Valparaíso y al Callao, se fué aminorando el entusiasmo en pro de una liga o confederación". Si bien los militarismos-caudillismos fueron condicionados por el sistema internacional, éstos, a su vez, también propagaron la incertidumbre y la idea de que el sistema latinoamericano era impracticable. La no compaginación entre el Derecho Internacional y el Derecho Interno; el militarismo; los ataques europeos en América, fueron, en suma, condicionantes del fracaso de las ideas latinoamericanistas (Urrutia, 1920:59-61; cfr. Uribe Vargas, 2005:100, 106, 195, cuando atribuye a la Diplomacia Secreta de Colombia en los casos de las guerras del Pacífico y otros asuntos, una disposición del pseudo-caudillismo y militarismo deformado de Tomás Cripriano de Mosquera).

LA HISTORIA DE LAS RELACIONES INTERNACIONALES EN COLOMBIA Una ojeada a la literatura sobre la fase republicana, 1820-1903 
y espiritual del pueblo, por un lado, y a la influencia de las corrientes internacionales imperantes de la época, por el otro. Obviamente que tales corrientes se adaptaban rápidamente a las características de la política interna de la nación. Por ejemplo, la corriente de ideas que más apetecían los historiadores colombianos, al igual que los responsables de la política exterior del siglo XIX, era lo que Urrutia Ilamaba "comunidad espiritual" procedente de las "ideas filosóficas francesas" (Urrutia, 1941:97-98, 102-103). Lo obvio radica en que con las condiciones precarias en que se mantenía Colombia durante el siglo XIX, mantener una posición de soberanía y neutralidad frente a las pretensiones imperialistas europeas o norteamericanas, una "comunidad espiritual" basada en el "espíritu" civilista forjado en el Derecho Internacional era más propicia e inteligente que una práctica desafiante e incluso intervencionista. En ese sentido, el Derecho Internacional se convirtió en el arma más efectiva -por lo menos en determinados casos- para la defensa de la soberanía de los nuevos estados nacionales constituidos a partir, precisamente, de la desmembración imperial. ¿Pero qué sucede cuando ese

El espíritu latino/panamericano es recurrente en los autores que narraron sus historias diplomáticas a partir de 1920. Creen que las conferencias latinoamericanas hasta 1889 (año en que se lleva a cabo la Conferencia de Washington o Primera Conferencia Panamericana) fracasaron por la ausencia de Estados Unidos: "La armónica marcha de los Estados americanos no puede asegurarse sino mediante el concurso de la República de los Estados Unidos del Norte, cuyo poderío, cuyos inagotables recursos, cuya influencia en la sociedad universal de las naciones son, a no dudarlo, muy eficaz garantía de los propósitos y acuerdos de las Dietas americanas" (Urrutia, 1920:65; Rivas, 1961:750, 754 y 760). Pero el Tratado sobre Arbitraje, su principal discusión, no sería ratificado, debido a los intereses de cada uno de los Estados, que se resumen en su pretensión de crear un Derecho antes que delinearlo y el afán de evitar la guerra por cualquier medio, mostrando que podrían ser igual de civilizados que los europeos. Por tal razón se convoca la Segunda Conferencia Panamericana de México de 1902:

“Todo pretexto desapareció para que se creyera que el Gobierno de Washington quería hacer de la Conferencia americana un instrumento para consolidar su influencia política y comercial en el Continente, mediante el establecimiento de un Zollverein americano o mediante la consolidación de la hegemonía, por la probable designación del presidente de los Estados Unidos para árbitro de las disputas". Defiende la Conferencia y asume como infundado este temor: "el hecho es que a la labor y a los acuerdos de la Conferencia de Méjico se debe el que acentuara la fe en los resultados provechosos generales para los Estados de América que debían derivarse de las Dietas americanas" (Urrutia, 1920: 75-76).

Acusaron estos autores que las Relaciones Internacionales de América Latina frente a Estados Unidos fueron en un principio precarias, debido a las preocupaciones de la política interna, o al descuido de ésta, tales como "la falta de educación adecuada para el nuevo régimen político"; el tradicionalismo político (caudillismo y militarismo); la falta de problemas y de preocupaciones de orden económico, o mejor dicho, la falta de comprensión de esos problemas. La salvación estaría en los ideales de hombres de estado que "principian a levantar la vista más allá de las fronteras patrias y a preocuparse de intereses y problemas comunes a los otros pueblos americanos" (Urrutia, 1920: 239-240; cfr. también Caicedo Castilla, 1974:254). En resumen: no se trata de ingenuidad, sino de una forma de historiar que mezcla el romanticismo de una época de libertad, con la objetividad que le permite el documento y, por último, la interpretación personal del historiador. 
destino se desvía, es decir, cuando los gobernantes se ven en la necesidad de recurrir a otros preceptos ajenos al derecho internacional o a la diplomacia secreta? ${ }^{13}$.

Forzosamente, los autores de las historias diplomáticas han insistido en que la política exterior colombiana se proyecta "al ámbito internacional de manera consciente y continuada", y una forma contraria, como la diplomacia secreta, "ha sido en Colombia planta exótica de muy rara y difícil ocurrencia" (Uribe Vargas, 2005:30). Como la política exterior de los estados está dominada principalmente, aunque no exclusivamente, por hombres de estado, éstos, naturalmente, pueden incurrir en fallas fundamentales que sugieren ser tratadas en "historias menudas que infortunadamente merodean tras la gloria de los grandes hombres" (Uribe Vargas, 2005:31). Una Historia Diplomática de Colombia usualmente introduce la narración presentando la personalidad y el carácter de cada uno de los miembros ilustres de las clases altas. Por ejemplo, Diego Uribe Vargas $(2005: 38,82,195)$ atribuye a la torpeza, ignorancia, enfermedades e intereses personales de los hombres de estado, "la interpretación más ajustada a la verdad histórica". En el mismo sentido, Raimundo Rivas (1961:749-750) justifica los errores y las negociaciones infructuosas como algo natural de las naciones con una historia reciente e inexperiencia en el campo de la política. Uribe Vargas catapultó las intenciones de la diplomacia secreta colombiana, frente a los casos de la supuesta monarquía constitucional de 1828-1830, y frente al caso del Tratado Secreto de Alianza con Perú, de 1866, en la guerra contra España. En ambos casos, sugiere Uribe Vargas, la diplomacia secreta es injustificada, pues ataca los cimientos de la vida civil de la República, esto es, sus cimientos legales y constitucionales. Como Uribe Vargas, el historiador Alberto Miramón (1956) aduce que el arte de la diplomacia y el discurrir del diplomático son causantes de grandes efectos en las relaciones entre los pueblos, pero que en esos tiempos, la diplomacia clásica ya debía ceder el espacio a la diplomacia moderna, abierta a la opinión pública y en beneficio de los intereses de todos los pueblos.

Por esas razones, los historiadores de la diplomacia tenían la urgencia de presentar al diplomático ideal, desaparecidos ya de la escena figuras como Bolívar y Santander, o los mismos Gual y Zea. Antes de eso argüían que la "diplomacia es parte principalísima de la Historia Nacional y no se puede amar a la Patria sin conocerla, ni conocer a sus hombres" (Otero, 1935:214). El tipo perfecto del diplomático era, ante todo, el que amaba la patria, y en el caso colombiano, el que respetaba y daba su vida por la defensa de la legalidad y la constitución, superando en esto a Bolívar el genio y espíritu irradiador de Santander (Liévano, Prol., 1973). Luego se introducían sus caracteres. El historiador Luis Alfredo Otero se refería así del diplomático y expresidente de Colombia de fines del siglo XIX, doctor Carlos Holguín:

\footnotetext{
${ }^{13}$ Con referencia a la diplomacia secreta, en mi artículo anterior hago un balance crítico aduciendo que ésta era también parte integral de la política exterior colombiana, sin representar mengua alguna al carácter civilista de la nación (Ghotme, 2007a).
} 
“[cumplía] el tipo perfecto del diplomático: alto, delgado, mirada suave, porte distinguido. De gran ilustración y feliz memoria, era atractivo en los salones, en los liceos, en los parlamentos y dondequiera que se presentaba oportunidad de dar expansión a sus facultades superiores. Como orador, su verbo era fluido y armonioso. Terrible en la réplica, acosaba a su adversario con su precisión y agudeza. De aquilatado valor en las lides de la política, fue el doctor Holguín el paladín más activo y culminante de su partido" (Otero, 1935:222).

El doctor Laureano García Ortiz fue uno de los primeros intelectuales políticos -además de canciller, embajador y profesor universitario-, en inocular semejantes pretensiones hidalguistas del diplomático perfecto. Antes de describir el tipo ideal del diplomático moderno, acusaba de los grandes cambios que se suscitaron en las relaciones internacionales en la primera mitad del siglo XX, aduciendo que eran tiempos en que las "cosas no dan lugar ni tiempo" a previsiones, como en la diplomacia clásica. Puesto que en los tiempos modernos la política internacional aparece como un problema para los países "no previsto e insospechado", ésta "requiere y exige solución urgente e inmediata"14. Decía el autor: "Hoy por hoy en nuestra Cancillería deben encontrarse al día, completos, organizados y listos, todos los expedientes de nuestros derechos territoriales, de nuestros intereses económicos, de nuestros antecedentes de doctrina internacional e historia diplomática [...]". El factor humano, esto es, el diplomático, es vital. Continúa García Ortiz:

"Hoy, más que nunca, son peligrosos los inexpertos y los improvisados.

“Que vengan los jóvenes, sí: de ellos es el campo; pero los verdaderamente inteligentes, los preparados por temperamento, por antecedentes y por estudio, los que a todo ello unan un buen carácter, que los lleve a resolver las dificultades en vez de crearlas, los que sepan atraer y no repeler, por excesiva pretensión y por carencia del don de gentes" (García Ortiz, 1946:790-791).

La denuncia que hiciera García Ortiz no sólo se limitaba al campo del diplomático ideal, sino a la temática que constituía el objeto de estudio de la Historia Diplomática. Tradicionalmente, como hemos visto, este tipo de historias se basa exclusivamente en la evolución de la política exterior colombiana vista "desde dentro», evolución que por lo demás se insertaba en la permanente búsqueda de la línea ascencional hacia el respeto, dignidad y honor en el concierto internacional (Cavelier, 1959, I: 118-119). Puesto que Colombia era un Estado recién constituido, semejante pretensión de verdad y objeto formal de estudio aparecía como naturalmente válido. Pero en la medida en que estas cuestiones tomaron consistencia, se agregaba una temática y metodología pluralista, sin abandonar su carácter y estilo de historiar

\footnotetext{
${ }^{14}$ Es de admirar que Laureano García Ortiz se había anticipado a las obras de historiadores que a fines del siglo XX recalcaron sobre el cambio irrepetible en el acontecer de la humanidad, del cambio acelerado e indeterminado por factores históricos, como el caso de B. Tucknam. Entre otras cosas, a este diplomático se debe la conclusión del tratado limítrofe con Brasil, el Tratado García Ortiz-Mangabeira.
} 
tradicional. Los temas clásicos eran, básicamente, los siguientes: límites, unión latinoamericana, paz y reconocimiento por parte de España y las demás potencias y los problemas relacionados con la seguridad fronteriza, los acuerdos comerciales y la codificación del Derecho Internacional. En la medida que estos temas eran evacuados con mayor o menor celeridad y profundidad intelectuales, sobrevenían otras temáticas como la de las relaciones culturales, los movimientos ideológicos y políticos, las corrientes del comercio mundial y los primeros intentos, aunque tímidos, de incorporar al estudio categorías como la de imperialismo o colonialismo (Vásquez Carrizosa, 1996, II:496 y ss.). Todos estos aspectos, en apariencia, como determinantes de la política internacional. Sin embargo, como veremos más adelante, la mayoría de estas obras seguían circunscritas en el conductismo clásico de percibir la política exterior como algo meramente emanado de los Estados (jefes de estado, más bien), y sus relaciones de poder más o menos equilibradas.

En balance: son narraciones con un carácter exclusivamente diplomático, limitado a interpretar la evolución del Estado como producto de los actos de los hombres políticos, las negociaciones, acuerdos, misiones diplomáticas y las motivaciones ético-morales. Vimos, además, que los académicos no negaron el valor de la vida material y los condicionantes externos de la política exterior, tales como el imperialismo europeo, las corrientes de pensamiento internacional y las ideas políticas imperantes; pero si bien no negaron ese valor, le dieron uno más profundo a la capacidad que tuviera el "gran hombre" para dominar -y si se quiere, crear- el devenir histórico. Por esa razón la investigación histórica comenzó a dar más peso en sus estudios a la óptica social y económica que aparentemente superaría los anacronismos y los vacíos analíticos que rodean la formación de la política internacional; las estructuras o fuerzas subyacentes, la vida material y caracteres de la civilización (Braudel, 2005) han permitido esbozar las relaciones internacionales ya no basadas en las relaciones entre los gobiernos, sino entre pueblos y estados.

\section{- Revisionismo transicional. De la Historia Diplomática a la Historia Estructural:}

A partir de la segunda mitad del siglo XX las obras clásicas de Historia Diplomática comenzaron a convivir paralelamente con otros estudios más estructurales de la política internacional. Este estructuralismo primitivo suponía que en la matriz de la política exterior de un estado existían entornos - para utilizar la terminología de los sistémicos modernos- que afectaban literalmente no determinaban- los procesos de elaboración, transformación, cambio y materialización de esa política. Los entornos son referenciados como elementos de la economía doméstica e internacional, el comercio, la cultura y carácter de los pueblos, las ideas y el reconocimiento apriorístico de un sistema internacional imperante, aunque esta última noción seguía siendo vaga o sugestiva. Sólo el determinismo sistémico sería imperante en los estudios de la dominación imperial y el equilibrio del poder de las décadas de 1980, 1990 e 
inicios del siglo XXI. En la tendencia revisionista intermedia, sin embargo, los entornos quedaban reducidos a eso: al entorno. Seguían creyendo que lo determinante del sistema internacional era la actuación racional -y en esto dependía el grado de poder- de cada gobernante, su conocimiento del entorno y el cálculo de las iniciativas de otros gobiernos. Veamos.

Algunos autores paradigmáticos en este campo fueron el propio Vásquez Carrizosa y el doctor Germán Cavelier. Comenzaron por revaluar la Historia Diplomática que, paradójicamente, adolecía de un sentido histórico, o, lo que es lo mismo, pecaban de un excesivo carácter ahistórico $\left(\right.$ Cavelier, 1959, I) ${ }^{15}$. Al emprender su estudio sobre la historia diplomática de Colombia del siglo XIX, referente a los límites y la diferencia con Estados Unidos sobre Panamá, Vásquez Carrizosa (1996, II: 484) introduce su estudio haciendo un recorrido por la "dilatada superficie con escasa población", donde "prevalecen la cultura literaria y la ignorancia de la economía". Este autor rompe el hilo de las narraciones tradicionales para darle un contorno más estructural a los determinantes de la política exterior colombiana. Además de incluir un estudio de las fuerzas subyacentes de los pueblos, su carácter, genio, peculiaridades y diversiones, incorporaba un análisis de las corrientes literarias dominantes en Colombia y el mundo (Vásquez Carrizosa, 2000, I: 17-18). También hizo un recorrido por los determinantes económicos:

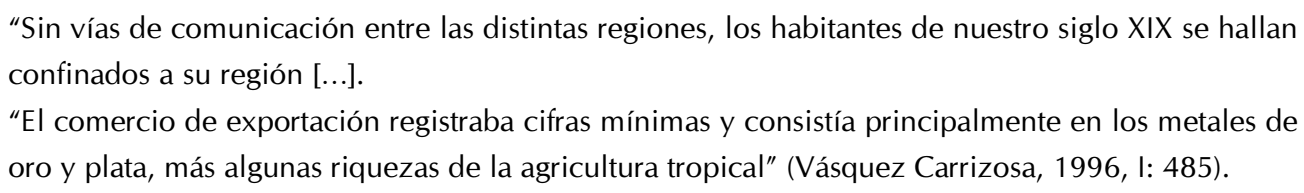

Vásquez Carrizosa sigue la tradición del revisionismo histórico liberal que apareció en Colombia en la segunda mitad del siglo XIX, donde la economía nacional de la post-independencia era concebida como heredera del sistema colonial. Agregó que el "atraso económico y social está ligado a la inexistencia de un sistema monetario de alguna solidez" (1996, I: 490, 492). Entre diversos ensayos de convertibilidad de la moneda, el diagnóstico bimetálico del oro y la plata como patrones intercambiables durante casi todo el siglo XIX, llevaron a Colombia a tener un "sistema monetario casi nulo" por la cantidad excesiva de circulante extraoficial y la aparente escasez de oro a fines del siglo XIX. Para Vásquez Carrizosa (1996, II) y Raimundo Rivas (1961:760) era imprescindible el análisis previo de las condiciones económicas del país como requisito previo para ensanchar la política exterior. No sólo insistían en el precio de los metales, su convertibilidad basada en "las monedas extranjeras como el franco francés y la libra esterlina", las inequivalencias del metal colombiano que hacían imposible su

\footnotetext{
${ }^{15}$ Paradójicamente, también, estos autores siguieron titulando sus obras como "Relatos de Historia Diplomática", en el caso de Vásquez Carrizosa, o "La Política Internacional", en el caso de Cavelier. Este último conserva la tradición -en cierto modo inglesa- de percibir las relaciones internacionales como parte integral de la historia, con sus ramificaciones para cada parcela de la realidad, en este caso, la «política internacional».
} 
circulación, además de la inexistencia de una política monetaria centralizada (hasta 1886), sino que atribuía al papel del comercio internacional el carácter impostergable para desarroIlar una política exterior firme (Vásquez Carrizosa, 1996, II: 491).

Sin embargo, Vásquez Carrizosa (1996, II:490, 494) y Rivas (1961:754), convencidos de la insuficiencia del método estructuralista por sí solo, terminan admitiendo que "el atraso de nuestro país se lo atribuimos a la falta de economistas formados para estudiar los problemas estructurales de una nación que vivía el periodo de la hacienda y de las transacciones de bienes primarios", o, en palabras más prácticas, al hecho de que "muy pocos jefes de Estado podían ver la economía de sus países" con claridad. Parafraseando a Renouvin (1960, Intro. Gen.; 1960, II, I: 631-637), podemos sintetizar esta postura de los revisionistas intermedios: una historia basada exclusivamente en determinantes sociales y económicos también es insuficiente; no da cuenta, por ejemplo, del papel de los grandes hombres y la política (de paz, sobre todo) para conducir los parámetros básicos de los flujos comerciales y la vida material. Esta posición intermedia, como se ve, seguía asumiendo que los factores socioeconómicos, culturales e ideológicos eran básicos para entender cómo se elaboraba, ensanchaba y materializaba la política exterior colombiana, antes que aceptar que esa política también podría ser determinaba por factores exógenos del entorno. Sin duda, esa posición obedecía también al carácter dual de los autores: funcionarios y académicos, lo que los limitaba a actuar dentro de los parámetros de la oficialidad.

\section{LA HISTORIA REVISIONISTA}

Al mismo tiempo, aquella tendencia revisionista fue evolucionando hacia dos formas de historiar las relaciones internacionales de Colombia: la primera, la del «autonomismo», basada en el análisis histórico estructural de la política exterior (Randall, 1992), o la del «equilibrio del poder», basada en el juego cuidadoso para el posicionamiento de intereses frente a las grandes potencias (Clemente Batalla, 2000). Entre el autonomismo y equilibrio del poder existe una tendencia media conocida como «estudios de la subordinación», en el que la política exterior se entiende como el desarrollo histórico de parámetros económicos y culturales que, por ciertas condiciones arrojadas al azar, quedan subordinadas, tanto la nación como su política exterior, a otra nación más civilizada (Díaz Callejas, 1997). En aras de la sencillez, esta primera tendencia la ubicaremos como la escuela del «equilibrio del poder», aunque por su contenido y aplicación, la de la subordinación se acerca más a la segunda. La segunda se refiere a los «estudios del imperialismo» en perspectiva de la investigación histórica, que ubica la política internacional dentro de la lógica sistémica de causa-efecto entre el capitalis-

LA HISTORIA DE LAS RELACIONES INTERNACIONALES EN COLOMBIA Una ojeada a la literatura sobre la fase republicana, 1820-1903 
mo, la nación-estado y el imperio como determinante de la política exterior (Vega, et. al., 2003; Díaz Arenas, 1998) ${ }^{16}$. Veamos.

- Los estudios del «equilibrio del poder»:

Buena parte de los politólogos o internacionalistas que se dedicaron al estudio de la política exterior colombiana durante las décadas de 1980-1990, como Diego Cardona (1992, Prol.), Pardo y Tokatlián (1988), o Drekonja, comenzaron a aplicar el estudio de la interdependencia compleja al análisis y proyección de la política exterior nacional, según ellos, partiendo de un contexto histórico. Asumen que las posibilidades de tal proyección surgen de las prácticas dominantes de las grandes potencias, pero que no podrían subsistir sin la oferta de algún recurso del dominado, lo que a su vez sería el punto de inflexión que deberían aprovechar esas sociedades rezagadas ${ }^{17}$. Randall (1992:17) emprende su estudio basándose en la "presunción de que las relaciones exteriores deben considerarse de modo integral, incluyendo vínculos culturales, comercio e inversiones, así como las relaciones políticas y militares generales". Tal presunción, aplicada al estudio histórico de las relaciones entre Colombia y Estados Unidos, parte de categorías de análisis sociales, como la seguridad e interés nacional y la ideología de cada país involucrado. Si bien los estudios de la autonomía relativa contextualizan históricamente a los países en cuestión, se centra más en concebir la autonomía relativa de Colombia durante las guerras civiles o la cuestión de Panamá como relaciones entre la potencia y sus dinámicas de negociaciones frente al poder real o nominal en una situación de debilidad interna y crisis institucional (Randall, 1992:61-88).

Una investigación realizada en Londres por Isabel Clemente Batalla (2000:2-3) "con base en una evaluación del contexto internacional que revelaba profundas contradicciones entre los intereses de [las] grandes potencias", insiste en que el carácter de las relaciones internacionales de Colombia en el siglo XIX estuvo basada en una "política de equilibrio con un propósito de defensa de la soberanía nacional". Esta autora parte de un examen del marco global en que se suscitaron las relaciones trilaterales entre Colombia, Estados Unidos y Gran Bretaña. Para tal fin, divide su estudio en cuatro fases: a) 1832-1846, fase de equilibrio exitoso para

\footnotetext{
${ }^{16}$ En esta tendencia aparece la obra - ¿tardía?- de Vásquez Carrizosa, quien admite que "El efecto de la inserción de las naciones periféricas al circuito de la riqueza y del comercio dirigido desde los centros, fue la desigualdad de los términos de intercambio a nivel internacional, entre los altos precios de los artículos manufacturados y los bajos de las materias primas, agravándose la condición de pobreza de los países periféricos" (Vásquez Carrizosa, Prol., 1998:11). Sería interesante promover la realización de una síntesis, desde la óptica de la Historia de las Ideas Políticas, de la obra variable de Vásquez Carrizosa, tarea que debiera ser reservada para otros espíritus y voluntades.

17 Una versión más contemporánea del autonomismo fue remozada por el mismo Centro de Estudios Internacionales de la Universidad de los Andes, con la rúbrica de la teoría constructivista?.
} 
Colombia. El resultado más visible de esta fase fue la elaboración del Tratado Clayton-Bulwer de 1850, "una obra maestra de orfebrería política" que garantizaría hasta 1901 la neutralidad y soberanía de Colombia en el Istmo (Clemente Batalla, 2000:34) ${ }^{18}$; b) 1846-1878, fase en que la política de equilibrio decrece por la presión norteamericana sobre el Istmo. Esta etapa, que la autora Ilama de "equilibrio inestable", se caracteriza por una conflictiva relación, agudas controversias y una continua desconfianza entre Gran Bretaña, Estados Unidos y Colombia, que se acercaba cada vez más a potencias europeas, como Francia o Alemania. El equilibrio radicó básicamente en que Colombia mantuvo cierto grado de maniobrabilidad autónomo con referencia a otras potencias europeas (Clemente Batalla, 2000:36); c) 1878-1888, fase conflictiva entre las tres naciones, tanto por la debilidad interna de Colombia (v.gr. guerras civiles), como por el desplazamiento contundente de Gran Bretaña por parte de Estados Unidos en la región. En esta fase Colombia tuvo su último aliento de equilibrio, buscando autónomamente la neutralidad del Istmo en Europa. Con la ayuda solicitada por Colombia a Estados Unidos en la guerra civil de 1885, aquel país sentenció al abandono su política de neutralidad hacia las potencias europeas (Clemente Batalla, 2000:56, 62-64 y 72); y d) 18881904, cuando se da el fin del equilibrio y el reafianzamiento de la hegemonía norteamericana, con la subsiguiente desmembración de Panamá (Clemente Batalla, 2000:74).

A diferencia de Vásquez Carrizosa, Clemente Batalla (2000:79-80) concluye diciendo que Colombia sí tenía un conocimiento claro del orden mundial imperante y de las corrientes de pensamiento, ideología y tendencias imperiales del periodo 1845-1903. Desconocimiento que, según Vásquez Carrizosa (1996, II: 503), Ilevó a Colombia a dar "un paso fatal en nuestra historia diplomática". Sin embargo, como en el caso de Randall, Clemente Batalla tiende a sobrevalorar los documentos diplomáticos y darles una validez incontrastable frente a las interpretaciones de los académicos y los estudios imperiales o colonialistas. Además: parten de la elaboración de categorías de análisis que luego son probadas en el laboratorio de la historia, desconociendo algunos factores que son propios de los acontecimientos, de los hechos que en cierta forma no siguen la misma línea de esas categorías.

- De la «subordinación» y el «imperialismo»:

Por otra parte, existen también estudios de las relaciones internacionales de Colombia que se encargan de establecer el balance en el equilibrio del poder entre Gran Bretaña y Estados Unidos, pero encasillado en los estudios en torno al imperialismo y al colonialismo. Estos estudios comenzaron por emprender una fuerte crítica a los trabajos de la Historia Diplomáti-

\footnotetext{
${ }^{18}$ Curiosamente, tanto Clemente Batalla como Randall coinciden en que durante la administración del General Santander de 1832 a 1837 es cuando más activa, realista y eficaz fue la política del equilibrio del poder. Lo curioso estriba en que para los académicos tradicionales, Santander estaba normalmente opacado por la política romántica e idealista de Bolívar incluso después de su muerte.
} 
ca y a los defensores de la postura de un Derecho Internacional Americano -o sistema internacional americano-, que propugnaba, hasta finales del siglo XIX, varios propósitos mancomunados (Supra, nota 12, en particular la visión tradicionalista de Yepes, 1955; Urrutia, 1920, 1928; Rivas, 1961).

Para Vásquez Carrizosa (1996, II:501), por ejemplo, "las relaciones diplomáticas de la Nueva Granada, la Confederación Granadina, Estados Unidos de Colombia y la República de este nombre [...] estuvieron subordinadas a la intervención de Estados Unidos entre 1846 y 1903", además del desplazamiento lento y paulatino del dominio británico en Colombia. Esta situación se vio claramente reflejada en el Tratado Mallarino-Bidlack de 1846, que para Vásquez Carrizosa tenía un carácter sombrío, secreto, y que para el gobierno del general Mosquera representaba un descuido completo de la política internacional de entonces. Vásquez Carrizosa (1996, II:500-501), además, cree que este episodio representa una versión fluida, pero distorsionada de la Doctrina Monroe, que en conjunto con el "Destino Manifiesto", había emprendido la carrera imperialista norteamericana en contravía de los intereses británicos, venidos cuesta abajo desde 1850; concluye que por el Tratado Clayton-Bulwer entre Estados Unidos e Inglaterra, ésta "debía retirar todo proyecto de ocupación en las tierras vecinas del futuro canal interoceánico". Entre dos corrientes opuestas, el liberalismo y el imperialismo, Vásquez Carrizosa discurre por la política internacional en un aparente debate personal entre el conductismo reducido a una simple inoperancia de los jefes de estado, y el sistemismo explanado por los «tentáculos absorbentes del imperio».

Pero un análisis más detallado de la literatura liberal de finales del siglo XX deja en claro que la posición colombiana de autonomía relativa, o mejor, de su subordinación, está ensanchada por sus problemas internos, la corrupción, el rezago industrial, moral y racial (Díaz Callejas, 1997). Semejante fenómeno había sido expuesto de una manera más original por liberales radicales de la segunda mitad del siglo XIX. Florentino González, uno de los más conspicuos santanderistas radicales ${ }^{19}$, adujo en 1857 que Colombia necesitaba una reforma constitucional que, entre otras cosas, sin hacer perder la nacionalidad nominal neogranadina, la incorporaría a una nación poderosa, como parte de una confederación de provincias o estados americanos. La idea consistía en anexionar a los estados confederados neogranadinos a la Confederación de América del Norte, y de esa forma tener las mismas ventajas que pudieran tener Nueva York o Pensilvania: industrialización, defensa de la soberanía, medios de transporte avanzados, y, lo que más enfureció a los conservaduristas, la secularización del Estado y la superación del problema racial (Moreno Arango, 1940). ¿Podría esto indicar que la posición de subordinación de Colombia obedecía más a la posición expansionista o imperialista de las

${ }^{19}$ En otra parte hice un análisis del modelo santanderino de nación política y cultural; véase mi artículo en Ghotme, $2007 b$. 
grandes potencias, o, por el contrario, a una posición consciente o realista de los políticos colombianos frente a una posible anexión voluntaria?, o, del mismo modo, ¿no le quedaba más remedio a Colombia que emprender una depuración racial, económica y cultural? El hecho es que para Díaz Callejas (1997: 136 y ss.) la edad de oro de la diplomacia colombiana, esto es, la santanderista, había sido desplazada por la edad de los dirigentes inoperantes, de la nación perezosa y tropical y de la subordinación real hacia Estados Unidos y Gran Bretaña. La consecuencia más desastrosa de todo este proceso de decrecimiento nacional, fue, para Díaz Callejas, sin duda, la separación de Panamá. Como en la de Vásquez Carrizosa, la obra de Díaz Callejas circunscribe la debilidad y la subordinación de la política colombiana a sus problemas internos; pero a diferencia de Vásquez Carrizosa, el imperialismo en Díaz Callejas supone una especie de sistemismo aún más reducido a las circunstancias imperantes en el entorno nacional colombiano o norteamericano.

Uno de los analistas más conspicuos del imperialismo como determinante de las relaciones internacionales, Pedro Agustín Díaz Arenas (1998:191), se fue lanza en ristre justamente contra Santander y los prolegómenos de la nación santanderina. En modo alguno, Santander y Bolívar tampoco escapan a los debates historiográficos de las relaciones internacionales, e incluso sobreviven en los defensores de una postura estructuralista, allende su aversión por los «grandes hombres». El hecho es que Díaz Arenas adopta una posición marxista del bolivarianismo, como su postura política personal en contra del monroísmo. Díaz Arenas acusa al monroísmo de debilitar la posición latinoamericana de unión y confederación, propiciando más bien provincialismos azuzados por las oligarquías nacionales (léase Santander y los santanderistas) sometidas posteriormente al poder imperial institucionalizado por Estados Unidos ${ }^{20}$.

Es notable, pues, que para los marxistas el imperialismo es causante -determinante- de la historia interna de Estados Unidos y América Latina (Díaz Arenas, 1998:23; Vega, et. al., 2003:26), es decir, como una historia determinista en la que el imperialismo -sistemacondiciona la política interna e internacional. Tanto la obra de Díaz Arenas como la de Renán Vega tratan de mostrar cómo el Panamá colombiano fue una invención norteamericana que quería incorporarla al capitalismo mundial. Arrastrada por la fuerza del imperialismo, a Estados

\footnotetext{
${ }^{20}$ Refiriéndose al panamericanismo Díaz Arenas (1998:195-196), dice: “La mayoría de los historiadores burgueses y los gobernantes estadounidenses definen el panamericanismo como movimiento por la unidad americana basada en proximidad geográfica, similitud de instituciones, cooperación de intereses económicos, tendencia a los principios democráticos y comunidad de aspiraciones y objetivos internacionales.

"Dichas definiciones tergiversan la realidad histórica. El panamericanismo, en la acepción más moderna del vocablo, es un movimiento creado y aplicado por EU en la época del imperialismo continental para someter más a los pueblos de las Américas a su hegemonía política y económica. El panamericanismo [y por tanto la figura del arbitraje] es uno de los instrumentos de EU que propicia en los países de América Latina la creación de condiciones favorables para los capitalistas estadounidenses y desfavorables para sus competidores europeos".
} 
Unidos le correspondía la misión histórica -y aquí suponemos que por historia entienden algo así como azar- de civilizar a los pueblos que no se adaptasen a sus preceptos imperiales. Creen que los dos componentes básicos que Estados Unidos supo adecuar a esa suerte, son, como ya sabe incluso el analista que estudia la actual guerra de Irak o Afganistán, el Destino Manifiesto y el Panamericanismo (Díaz Arenas, 1998:194; Vega, et. al., 2003:35 y ss.). Ambas como manifestaciones ideológicas del monroísmo.

A diferencia de Vega, quien concibe una sola clase de imperialismo norteamericano, el brutal y despiadado imperialismo financiero-monopolístico, para Díaz Arenas el imperialismo norteamericano atravesó por tres fases en el siglo XIX ${ }^{21}$ : la fase de los asentamientos colonizadores contra los indios; la fase del colonialismo nacionalista (expansión territorial); y la fase del imperialismo continental (Díaz Arenas, 1988:179). Todas estas fases marcadas por un orden económico basado en el mercantilismo, el capitalismo y la esclavitud (cfr. Díaz Callejas, 1997:156 y ss.). Como buenos marxistas, concebían que la sociedad norteamericana estaba atravesada por la contradicción dialéctica de la prosperidad, la discriminación y el racismo (Vega, et. al., 2003:48, 60 y 100), que entre otras cosas fueron transplantadas por los filibusteros norteamericanos en el Caribe, Centroamérica y el Istmo a través de endémicas guerras raciales. Sus estudios, por tanto, arguyeron que "[...] hay un vínculo de causa efecto entre capitalismo emergente o mercantil y las primeras naciones, de igual manera el calificativo de imperial, en sentido moderno de dominio de una nación sobre otras [...]" (Díaz Arenas, 1998:23).

Por último, los estudios marxistas sostienen que las necesidades económicas y financieras de los hombres de negocios y los pueblos contienen un interés expansionista, que a su vez generan competencias que tienen que ser resueltas por medio de relaciones políticas. Del mismo modo, le atribuyen un carácter determinante al progreso de las técnicas industriales en la conducción de las guerras; a las condiciones demográficas y migratorias, en fin, caracteres todos determinantes de las relaciones entre los estados.

Ahora bien, si se estipula que lo económico es un móvil de las relaciones internacionales, en el sentido de acrecentamiento de los antagonismos -para utilizar la expresión favorita de Renouvin-, ¿no excluye esta presunción que alguna vez existieron capitalistas deseosos de la paz?, como fue el caso a fines del siglo XIX. O lo que es más: ¿se puede demostrar que existe una relación causal entre los intereses de los grandes capitalistas y las intenciones de los estados donde tienen su casa matriz esos intereses financieros?, ¿obedece siempre a una lógica de alianzas o empresas enviadas por los estados a conquistar los territorios periféricos? Es sabido que entre la aparición de las formas de capitalismo monopolístico del siglo XIX y la marcha normal de las relaciones internacionales habían razones de sobra para creer que existían

\footnotetext{
${ }^{21}$ Sin contar la que él considera cuarta fase para el siglo XX, es decir, la fase del imperialismo global o planetario.
} 
muchos lazos estrechos, relaciones estructurales y de contingencia que se forjaron al calor de las intervenciones imperiales (Renouvin, 1960, II, I:17). Con el ascenso meteórico de la burguesía liberal, plasmado en las ideas y la propia política práctica, los estados imperiales se vieron cada vez más impelidos a propugnar por una política exterior configurada por el avance de la industrialización y la mayor generación de riquezas. También es cierto, empero, que muchos inversionistas norteamericanos en Colombia y América Latina no tenían lazos o intereses algunos en perpetuar directamente la política exterior de su país de origen; por lo menos, y esto se lo cuestiona Renouvin (1960, II, I:472), "queda por saber si tales fines políticos habían estado determinados de antemano o si eran el resultado de una intervención diplomática cuyo objeto inicial fuera dar satisfacción a los intereses de los bancos y de los exportadores".

Tanto lo uno como lo otro están estrechamente entrelazados: el hecho es que la "Unión del Norte" utilizó a los inversionistas privados y sus empresas de capital mixto como un instrumento de su política exterior. Por tal razón la tendencia radical del imperialismo suele confundir las co-relaciones entre la economía y la marcha de las relaciones internacionales con las determinantes económicas que, en todo caso, son ineluctables en determinados casos. Los intereses económicos y financieros, en vez de ser una causa estrictamente, son más bien un instrumento (además de causas), un arma "en manos de los gobiernos que los utilizan al servicio de sus preocupaciones de seguridad o de prestigio" (Renouvin, 1960, I, Intro. Gen.: XII). Dicho en otras palabras: los móviles económicos configuran y determinan nuevas formas de la política internacional, pero para adquirir el prestigio y la seguridad requerida por los estados del sistema, pueden existir otros motivos allende la inversión y capitalización de las zonas de coloniaje. Los móviles económicos no son determinantes exclusivos.

Un par de cuestiones más: si aceptamos que las guerras son revoluciones a partir del siglo XVIII, las grandes decisiones políticas, los conflictos armados, en fin, ¿no es posible que pensemos en esas variables como determinantes del capitalismo, y no a la inversa? En ese sentido, incluso el sistema capitalista aparece como una prolongación de la marcha general del sistema de estados, y a la inversa, el sentido que adquieren las relaciones internacionales están configuradas por el moderno sistema capitalista. Lo segundo es que no son las grandes inversiones ni los inversionistas los que dominan el escenario de la guerra. Exceptuando algunos casos de injerencia "oculta" de parte de algunos inversionistas que promueven la guerra, a favor de sus intereses, es cierto también que ha habido momentos en que han promovido la paz. Por ejemplo, superados los remanentes del Ancien Régime, visibilizados con la Santa Alianza, sobrevino una etapa de las relaciones internacionales marcada por la perpetuación de la paz general, sistema conocido comúnmente como el Concierto Europeo. Si bien los grandes inversionistas, especuladores y banqueros se veían enormemente favorecidos con la promoción de una "crisis regional», la Cuestión de Oriente y muchas cuestiones más con un carácter localizado, como las guerras civiles en América Latina, también es cierto 
que la marcha general del sistema internacional se veía mucho más beneficiado con un circuito de comercio mundial en medio de la paz (Polanyi, 1997). Así dicho, la propia paz mundial pende también de un móvil económico: ya no sólo las rivalidades coloniales y el acrecentamiento del conflicto son consecuencia exclusiva de los intereses de los grandes inversionistas, incluido el Estado. De cualquier modo, existen pocas evidencias que indiquen que los grandes capitalistas hayan invocado o propiciado la guerra mundial de 1914. Las crisis estallan cuando entran en juego las pasiones y los arrebatos de los jefes de estado.

\section{CONCLUSIÓN}

Podemos comenzar por advertir que en Colombia no existe como tal una escuela institucional (una facultad, por ejemplo) de la Historia de las Relaciones Internacionales, exceptuando los trabajos de Historia Tradicional emprendidos por los intelectuales de la Academia Colombiana de Historia. Al separarse de la disciplina de las Relaciones Internacionales, que en el caso colombiano ocurrió en la década de 1980, la Historia Diplomática dejó de enseñarse en las universidades pero siguió su curso en las investigaciones de los académicos y los revisionistas, dando paso a trabajos sistémicos y marxistas. Sin embargo, estos últimos trabajos obedecen más a inclinaciones individuales de los autores, a tendencias teórico-sociológicas de alguna universidad o balances críticos que arremetieron contra la historia tradicional. En el mejor de los casos, ocurre que sus trabajos históricos son una elaboración sistemática de sus argumentos abstraídos de la teoría social, asemejándose más, de este modo, a una sociología de las relaciones internacionales. Pero ¿en el estado actual de la investigación podemos promover la creación de una escuela, maestría o doctorado en Historia de las Relaciones Internacionales? Dejemos la respuesta al destino. Sólo diremos que los departamentos de Relaciones Internacionales, Historia y Ciencia Política ni siquiera cuentan con cátedras formales con aquella materia que dio origen a esos programas académicos. Si no recuerdo mal existe un curso circunstancial en la Facultad de Derecho de la Universidad Nacional. Los demás dictan cátedras (queda la sensación que son complementarias) sobre Historia Internacional, Historia Contemporánea, etc. ¿Ingratitud?, ¿desprecio deliberado?

Entonces, ¿cuál es su importancia? Sin duda, la enseñanza de la Historia de las Relaciones Internacionales abre una posibilidad intelectual más para entender la conformación de las sociedades, tanto en su plano interno como externo, en especial si se trata desde ópticas multidisciplinarias. Las diferentes tendencias estudiadas en este ensayo prometen sendas pistas.

Como vimos, las historias con un carácter exclusivamente diplomático, que en términos de Renouvin (1960:IX), "toma el mismo horizonte que las cancillerías", suelen ser limitadas, puesto que trata de la evolución del Estado como producto de los actos de los hombres políticos, las negociaciones, acuerdos, misiones diplomáticas y las motivaciones ético-morales. 
Quien aquí escribe sigue creyendo, con todo, que el estudio de las actuaciones de los «grandes hombres» sigue siendo útil en el trasegar histórico: tanto sus iniciativas para mejorar -o denigrar- las condiciones sociales, económicas y demográficas; son quienes invocan en la opinión pública los sentimientos e ideas, como el nacionalismo; saben actuar racionalmente (a no ser que sean locos y magnicidas, como en efecto han habido en la historia de la humanidad), armonizando la política exterior con los recursos militares y económicos disponibles, en fin. Negar tal pretensión sería admitir otra pretensión de determinismo histórico, "hoy desmentido por tantas experiencias" (Renouvin, 1960, I: XI). Sin embargo, tal narrativa excluye otros fenómenos que la investigación histórica comenzó a incluir en sus estudios desde la óptica social y económica. La perspectiva de una historia de las relaciones internacionales basada en determinantes económicos y sociales, es decir, en las estructuras o fuerzas subyacentes, la vida material y caracteres de la civilización comenzaron a esbozar las relaciones internacionales ya no basada en las relaciones entre los gobiernos, sino entre pueblos y estados, pero, además, entre jefes de estado.

Por último, al elaborar un estudio historiográfico de las relaciones internacionales de Colombia durante la fase republicana (1820-1903), hemos tratado de llenar algunos vacíos en la literatura histórica e internacionalista que descuidaron tales aspectos. Ese vacío tuvo otro compañero de viaje que pudimos detectar en la investigación: la posición radical de los autores cuando asumen uno u otro aspecto de la teoría y la metodología de investigación. Aun cuando todos ellos elaboran un discurso previo en el que diseñan una narración multi-abarcadora, descubren conscientemente su predilección por una de las diferentes corrientes de pensamiento, sea el tradicional, el tradicional-revisionista, el revisionista-estructural, o el marxista. De todos modos, esto no es un pecado. Y casi todos terminamos convencidos del método más cercano a nuestros deseos.

En tal sentido, cuando abordemos la investigación histórica de las relaciones entre los pueblos y los estados, no se hará extraño al lector que encuentre una Historia de las Relaciones Internacionales encubierta por arrebatos de hombres y mujeres intelectuales y políticos que siguieron sus instintos, más allá de que fueran la síntesis de un complejo entramado de estructuras sociales, económicas y culturales.

\section{BIBLIOGRAFÍA}

Attinà, Fulvio, "El sistema político global. Introducción a las Relaciones Internacionales, Paidós, Barcelona, 2001

Bákula Patiño, Juan Miguel, "Colombia y el Perú. Relaciones Culturales”, en Boletín de Historia y Antigüedades, vol. LXIV, No. 507-509, Bogotá, 1957. 
Braudel, Fernand, "El Mediterráneo y el mundo mediterráneo en la época de Felipe II", vol. I, Fondo de Cultura Económica, México, 2005.

Caicedo Castilla, José, "Historia Diplomática", t. I, en Historia Extensa de Colombia, vol. XVII, Ediciones Lerner, Bogotá, 1974.

Cancelado, Henry, "Difracción del proyecto occidental en el sistema internacional contemporáneo: una reflexión teórica", en Revista de la Facultad de Relaciones Internacionales, Estrategia y Seguridad, Vol. II, No. I, Bogotá, 2007.

Cardona, Diego, Prólogo, "Aliados y Distantes", Tercer Mundo Editores, Universidad de los Andes, Bogotá, 1992.

Cavelier, Germán, "La política internacional de la Gran Colombia (1820-1860)", t. I, Editorial lqueima, Bogotá, 1959.

—-, "La política internacional de la Gran Colombia (1860-1903)", t. II, Editorial Iqueima, Bogotá, 1959.

Clemente Batalla, Isabel, "Relaciones Internacionales de Colombia en el siglo XIX: frente al desafío de las grandes potencias", Informe final, Proyecto de Investigación No. 905, Fundación para la Promoción de la Investigación y la Tecnología, Londres, 2000.

Caycedo, Bernardo, "Homenaje de la Academia Colombiana de Historia y de la Universidad Nacional al Profesor Arnold J. Toynbee", en Boletín de Historia y Antigüedades, vol. LXIII, No. 499-500, Bogotá, 1956.

Díaz Arenas, Pedro Agustín, "Relaciones Internacionales de dominación. Fases y facetas", Universidad Nacional, Bogotá, 1998.

Díaz Callejas, Apolinar, "Colombia - Estados Unidos. Entre la autonomía y la subordinación. De la independencia a Panamá", Editorial Planeta, Bogotá, 1997.

Duroselle, Jean-Baptiste, "Todo imperio perecerá. Teoría sobre las relaciones internacionales", Fondo de Cultura Económica, México, 1998.

Fulbrook, Mary, y Theda Skocpol, “Destined Pathways: the Historical Sociology of Perry Anderson", en Theda Skocpol, ed., Vision and Method in Historical Sociology, Cambridge University Press, New York, 1984. 
García Ortiz, Laureano, "Mis reminiscencias de la diplomacia. La política internacional de Colombia", en Boletín de Historia y Antigüedades, vol. XXXIII, No. 385, Bogotá, 1946.

Ghotme, Rafat, "Relaciones Internacionales de las Guerras Civiles. Colombia, 1885-1903", en Revista de la Facultad de Relaciones Internacionales, Estrategia y Seguridad, Universidad Militar Nueva Granada, Vol. II, No. I, Bogotá, 2007a.

-_, "Santanderismo, antisantanderismo y la Academia Colombiana de Historia. La operación histórica en el proceso de construcción de nación en Colombia, 1910-1970", en Anuario Colombiano de Historia Social y de la Cultura, Universidad Nacional, Bogotá, 2007b.

Grautoff, Manfred, “Capitalismo, Transnacionales y Migraciones Laborales en el Sistema Internacional Contemporáneo", Programa de Relaciones Internacionales y Estudios Políticos, Universidad Militar Nueva Granada, Bogotá, 2007 (copia mecanografiada).

Liévano, Roberto, Prólogo a Diego Uribe Vargas, "Colombia y la Diplomacia Secreta, Editorial Kelly, Bogotá, edición de 1973.

Meinecke, Friedrich, "El historicismo y su génesis", Fondo de Cultura Económica, México, 1943.

Meyer-Lindenberg, Hermann, "La organización de la paz", Ministerio de Relaciones Exteriores, Bogotá, 1937.

Miramón, Alberto, “Diplomáticos de la Libertad”, Empresa Nacional de Publicaciones, Bogotá, 1956.

Moreno Arango, Sebastián, "Historia y Diplomacia de los EE.UU. de Colombia”, Bogotá, 1940, s.e.

Otero, Luis Alfredo, "Internacionalistas y diplomáticos colombianos", en Boletín de Historia y Antigüedades, vol. XXII, No. 249-250, Bogotá, 1935.

Pardo, Rodrigo y Juan Tokatlián, "Política Exterior Colombiana: ¿de la subordinación a la autonomía?, Tercer Mundo Editores, Universidad de los Andes, Bogotá, 1988.

Pereira, Juan Carlos, et. al., "Historia de las Relaciones Internacionales Contemporáneas", Ariel, Madrid, 2001. 
Polanyi, Karl, "La Gran Transformación. Crítica del liberalismo económico", Ediciones de la Piqueta, Madrid, 1997.

Ragin, Charles, y Daniel Chirot, "The World System of Immanuel Wallerstein: Sociology and Politics as History", en Theda Skocpol, ed., Vision and Method in Historical Sociology, Cambridge University Press, New York, 1984.

Randall, Stephen, "Aliados y Distantes", Tercer Mundo Editores, Universidad de los Andes, Bogotá, 1992.

Renouvin, Pierre, "Historia de las Relaciones Internacionales", t. I, Introducción General, Editorial Aguilar, Madrid, 1960.

——, "Historia de las Relaciones Internacionales", t. II, vol. I, Editorial Aguilar, Madrid, 1960.

Rivas, Raimundo, “Historia Diplomática de Colombia, 1810-1934”, Imprenta Nacional, Bogotá, 1961.

-—, "Bolívar Internacionalista", en Boletín de Historia y Antigüedades, vol. XXV, No. 287288, Bogotá, 1938.

Theda Skocpol, "Sociology's Historical Imagination", en Theda Skocpol, ed., Vision and Method in Historical Sociology, Cambridge University Press, New York, 1984.

Smith, Anthony, "La Identidad Nacional," Trama Editorial, Madrid, 1997.

Ticckner, Arlene, "Los estudios internacionales en América Latina. ¿Subordinación intelectual o pensamiento emancipatorio?, Ediciones Uniandes, Bogotá, 2002.

Tovar, Bernardo, "La historiografía colonial", en La historia al final del milenio. Ensayos de historiografía colombiana y latinoamericana, Unal, Bogotá, 1995.

Uribe Vargas, Diego, “Colombia y la Diplomacia Secreta. Gestiones para implantar la Monarquía", Fundación Universidad de Bogotá Jorge Tadeo Lozano y la Academia Colombiana de Historia, Bogotá, 2005.

Urrutia, Francisco José, "Le Continent American et le Droit Internacional", Rousseau \& Cie., Editeurs, París, 1928. 
-, Páginas de Historia Diplomática. Los Estados Unidos de América y las Repúblicas hispanoamericanas de 1810 a 1830", Imprenta Nacional, Bogotá, 1917.

-_, La evolución del principio de arbitraje en América. La Sociedad de Naciones", EditorialAmérica, Madrid, 1920.

——, "Política Internacional de la Gran Colombia", Editorial El Gráfico, Bogotá, 1941.

Vásquez Carrizosa, Alfredo, "Relatos de historia diplomática de Colombia. La Gran Colombia", t. I, Ministerio de Relaciones Exteriores, Universidad Javeriana, Bogotá, 1996.

- - "Relatos de historia diplomática de Colombia. Los límites de Colombia y la diferencia con Estados Unidos sobre Panamá", t. II, Ministerio de Relaciones Exteriores, Universidad Javeriana, Bogotá, 1996.

- -, "Relatos de historia diplomática de Colombia. Siglo XX. Literatura y Política", t. I, Ministerio de Relaciones Exteriores, Universidad Javeriana, Bogotá, 2000.

-—, Prólogo a Pedro Agustín Díaz Arenas, "Relaciones Internacionales de dominación. Fases y facetas", Universidad Nacional, Bogotá, 1998.

Vega, Renán, Sandra Jáuregui y Luis Carlos Ortiz, "El Panamá colombiano en la repartición imperialista (1848-1903). Reconstrucción histórica a partir de las fuentes diplomáticas de Francia", Ediciones Pensamiento Crítico, Bogotá, 2003.

Yepes, J.M., “Del Congreso de Panamá a la Conferencia de Caracas, 1826-1954. El genio de Bolívar a través de la Historia de las Relaciones Internacionales", Caracas, 1955, s.e. 